\title{
Boca a Boca Virtual: Presença Digital para Pequenos Empreendedores
}

\author{
Pablo Cecilio, Antônio Pedro, Heitor Werneck, Leonardo Rocha \\ Universidade Federal de São João del-Rei \\ (cecilio,antonio.pedro,werneck)@aluno.ufsj.edu.br \\ lcrocha@ufsj.edu.br
}

\begin{abstract}
In this work, we present the platform Boca a Boca Virtual, a kind of virtual catalog that aims to help self-employed professionals and small businesses to start their presence in the digital environment, promoting their services and products in a simple and fast way. The idea emerged during the beginning of the COVID-19 pandemic, especially with social isolation, whose concern, from an economic and social point of view, was to allow autonomous service providers and establishments, in general, to continue offering their products and/or services. Through the platform, a consumer can search for a specific product and service within his own neighborhood and city, strengthening the local economy. In addition, Boca a Boca Virtual is integrated with Google Maps, in such a way that registered developments are also indexed by the Google search engine, improving their visibility and potentially increasing more customers. The platform is fully responsive, combining several recent web development technologies. Today it has more than 140 registered enterprises, from more than 30 Brazilian cities.
\end{abstract}

\section{Keywords}

Electronic Commerce, Small Businesses, Recommendation

\section{Introdução}

A pandemia do COVID-19 vem trazendo uma série de problemas ao redor do mundo, tanto do ponto de vista da saúde, quanto do ponto de vista social e econômico. No Brasil, a população vem sofrendo com essa doença desde março de 2020, quando grande parte do comércio e dos serviços não essenciais precisaram ser fechados. O impacto desse cenário foi enorme nas grandes empresas, mas a maior parte do problema refletiu nos trabalhadores informais e micro empresários. Segundo o IBGE (Instituto Brasileiro de Geografia e Estatística), em setembro de 2019 o Brasil contava com quase 40 milhões de trabalhadores informais, a maioria deles trabalhando como prestadores de serviços, na revenda de produtos ou como autônomos. Além disso, segundo o SEBRAE, o Brasil possui cerca de 6,4 milhões de estabelecimentos, sendo que desse total, $99 \%$ são de micro e pequenas empresas (MPE). Grandes empresas rapidamente se adaptaram a esse novo cenário reforçando ou iniciando suas presenças no mundo digital. Entretanto, para os trabalhadores informais e micro empresários, esse processo é mais complexo, seja por falta de recursos ou por falta de conhecimento e treinamento.Diante desse cenário que se desenhava a partir de março de 2020, quando se

In: XIX Workshop de Ferramentas e Aplicações (WFA 2020), São Luís, Brasil. Anais Estendidos do Simpósio Brasileiro de Sistemas Multimídia e Web (WebMedia). Porto Alegre: Sociedade Brasileira de Computação, 2020.

(c) 2020 SBC - Sociedade Brasileira de Computação.

ISSN 2596-1683 iniciou o processo de isolamento social, alguns alunos do curso de Ciência da Computação da Universidade Federal de São João Del Rei (UFSJ) demonstram preocupação quanto ao sustento de suas famílias, uma vez que seus pais eram trabalhadores informais ou pequenos comerciantes. Foi diante deste contexto que surgiu a ideia do Boca a Boca Virtual ${ }^{1}$, uma plataforma desenvolvida e mantida pelos alunos do curso de Ciência da Computação da UFSJ, cujo objetivo principal é auxiliar trabalhadores informais ou pequenos empresários a iniciarem suas presença no meio digital, divulgando seus serviços e produtos de uma maneira simples e rápida.

No Boca a Boca Virtual, o empreendedor, seja ele pequeno ou informal, pode cadastrar seus produtos e/ou serviços (seu empreendimento) provendo uma série de informações, tais como telefones e e-mails para contato, a categoria do produto e/ou serviço (i.e. alimentação, informática, etc.), cidade e bairro onde o mesmo funciona e uma descrição que permite a inserção de imagens ilustrativas. A plataforma também provê uma API de integração com o Google Maps (https://www.google.com.br/maps/), na qual o empreendedor pode informar a localização geográfica de seu empreendimento. Antes das informações do empreendimento serem publicadas pelo Boca a Boca Virtual, elas passam por uma analise no qual é verificado se as mesmas não ferem o propósito principal da aplicação. Essa análise é feita por um tipo de usuário específico, o qual denominamos de curador. Para que uma cidade seja cadastrada na plataforma, a mesma precisa de um ou mais curadores e, desse modo, cada curador é responsável pela análise dos empreendimentos cadastrados na cidade pela qual ele é o responsável. Um terceiro ator nessa plataforma é o Administrador, responsável por realizar o cadastro de curadores, inserção de novas cidades, criação de novas categorias e todas as demais atividades de administração da plataforma. Com o cadastro do empreendimento aprovado pelo curador, o mesmo passa a ser divulgado pela plataforma. Por meio desta, os consumidores que procuram por algum produto ou serviço são capazes de realizar buscas de uma maneira simples e rápida, com diversos filtros que podem ser combinados: filtro por cidades, por bairros e por categorias de produtos. Além disso, por meio de um plugin de integração com o Facebook (https://facebook.com), os consumidores podem deixar comentários sobre os produtos e/ou serviços, digitalizando a tradicional propaganda de boca a boca.

O Boca a Boca Virtual é uma aplicação Web, totalmente responsiva, e que combina o uso de diversas tecnologias, tais como RESTful API [2], PostgreSQL [5], Angular [3], Google Maps [4] e SENTRY [8]. Todo o desenvolvimento foi feito, bem como todas as manutenções corretivas e evolutivas que vêm ocorrendo,

\footnotetext{
${ }^{1}$ https://dcomp.ufsj.edu.br/bocabocavirtual/
} 
sem nenhum recurso financeiro, apenas por meio do trabalho voluntário dos três alunos autores desse projeto, sob a coordenação do professor Leonardo Rocha. Além disso, o Boca a Boca Virtual contou, e ainda conta, com a colaboração de outras muitas pessoas, seja no processo de divulgação por meio das redes sociais, seja por meio do papel de curador na plataforma. Atualmente, o Boca a Boca Virtual conta com mais de 140 empreendimentos cadastrados em mais de 35 cidades distribuídas por 5 estados do Brasil. Grande parte dessas cidades são do interior de Minas Gerais, composta majoritariamente por pequenos produtores rurais, prestadores de serviços e artesãos. Pelo contato mantido com as secretarias municipais dessas várias cidades, o retorno e a aprovação dessa plataforma tem sido muito positiva. Primeiramente porque o Boca a Boca Virtual, associado a campanhas de publicidade, tem incentivado o consumo de produtos locais, fortalecendo as economias regionais. Em segundo lugar, a API que integra o Google Maps tem possibilitado que esses empreendimentos sejam indexados pela própria máquina de busca do Google. Se antes esses produtos, serviços e empreendimentos eram apenas conhecidos localmente, sem referência na Web, agora, com a indexação desses dados pelas máquinas de busca, tem aumentado consideravelmente seus potenciais consumidores. Um exemplo que ilustra bem esse cenário é a cidade de Resende Costa, conhecida localmente pelas diversas empresas familiares de artesanato têxtil, vem recebendo atenção e contatos de diversas cidades do Brasil. A médio e longo prazo, nossa expectativa é que, a medida que tenhamos uma maior divulgação por parte das mídias, não apenas as locais ${ }^{2} 3$, poderemos ampliar ainda mais o total de cidades e pequenos empreendedores atendidos.

\section{Arquitetura e Tecnologias}

A plataforma Boca a Boca Virtual foi criada para permitir a utilização das melhores ferramentas de desenvolvimento para sua construção. Nesse sentido, utilizamos uma RESTful API [7], que permite a comunicação do servidor com dados - também conhecido como back-end - com a aplicação que os usuários interagem - conhecida como front-end. Para o desenvolvimento de nossa RESTful API (ou simplesmente, API), utilizamos o Django REST Framework [2]. Este framework possui diversas vantagens, dentre elas destacam-se a fácil navegação nos recursos disponíveis, bem como o envio de formulários, utilizado nas funcionalidades de cadastro da plataforma (i.e. cadastro de empreendedores).

No lado do back-end, os dados passados pela API são armazenados em um banco de dados relacional, cujo SGBD (Sistema de Gerenciamento de Banco de Dados) é o PostgreSQL [5]. O PostgreSQL, além de ser gratuito e amplamente utilizado no mercado, possui facilidades para o armazenamento de dados geométricos, que foram fundamentais para a integração dos empreendimentos cadastrados na plataforma com a API do Google Maps [4]. Em outras palavras, o uso de dados geométricos permite definir uma geolocalização, que é utilizada para indexar qualquer estabelecimento, ou negócio, no Google. Assim, consegue-se ampliar a presença digital de pequenos negócios, tornando-os acessíveis na maior máquina de busca do mundo.

No front-end, visando a construção de uma aplicação intuitiva e escalável, utilizamos o Angular [3], uma tecnologia recente, mas de

\footnotetext{
${ }^{2}$ https://www.otempo.com.br/o-tempo-betim/federal-de-sao-joao-del-rei-criacatalogo-online-de-pequenos-empreendimentos-1.2330929

${ }^{3}$ https://youtu.be/3AbvGhBOcV8
}

fácil manutenibilidade e extremamente flexível para a adição de novas funcionalidades. O design do front-end foi feito com o framework Materialize [6], que provê elementos visuais limpos e intuitivos.

Vale destacar que na plataforma Boca a Boca Virtual utilizamos ferramentas auxiliares de monitoramento para descobrir erros em tempo real, tanto no back-end quanto no front-end. Essa tarefa foi realizada com o SENTRY [8], que possibilita diagnosticar e antecipar problemas na plataforma, garantindo estabilidade e segurança para os usuários. Implementamos também uma outra ferramenta auxiliar que monitora (e.g. um BOT) o cadastro de novos empreendimentos e notifica os curadores responsáveis pela cidade onde o empreendimento está sendo cadastrado no intuito de prover uma resposta rápida. Tanto as ações do SENTRY como do BOT construído foram incorporadas ao Slack [9], facilitando a comunicação da equipe para desenvolvimento e manutenção da plataforma.

A plataforma utiliza o Apache HTTP Server [1] como servidor web, habilitado com o modulo Python para permitir o funcionamento da API e das ferramentas de monitoramento. Na Figura 1 ilustramos a integração de todas as ferramentas de desenvolvimento utilizadas na construção do Boca a Boca Virtual. Com exceção das ferramentas de monitoramento e da API do Google Maps [4], todas as demais soluções e tecnologias utilizadas são de caráter Open-source, permitindo várias fontes de suporte e integrações para o sistema.

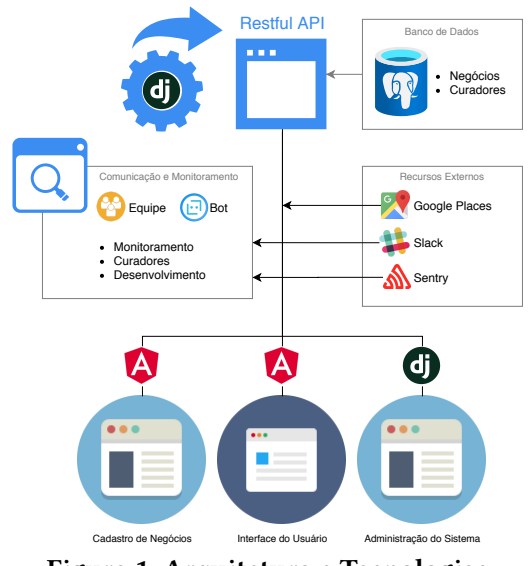

Figura 1: Arquitetura e Tecnologias

\section{Funcionalidades da Ferramenta}

O Boca a Boca Virtual possui quatro atores importantes para o seu funcionamento, são eles: empreendedores (ou autônomos), curadores, administradores e consumidores. A interação entre eles e a visão geral do processo de funcionamento da plataforma é ilustrado na Figura 2. A seguir, detalhamos o papel desses atores e as funcionalidades disponíveis para cada um deles.

\subsection{Quem são os usuários?}

Como dito, quatro tipos de usuários atuam no Boca a Boca Virtual, pequenos empreendedores, curadores, administradores e consumidores. Os empreendedores são a força motriz da plataforma e são responsáveis por cadastrar seus negócios, preenchendo o modelo de anúncio virtual do Boca a Boca Virtual. Para que o empreendimento possa ser cadastrado para uma determinada cidade, a mesma precisa de um ou mais curadores. Os curadores são responsáveis por verificar se as informações preenchidas pelos empreendedores não 
possuem conteúdo impróprio, abusivo ou que desviam da finalidade do Boca a Boca Virtual. Caso algum desses problemas ocorra, o comerciante é notificado e pode reenviar seu anúncio com as correções necessárias. Já o anúncio que atende a finalidade da plataforma é aprovado pelo curador e disponibilizado. Os administradores, além de serem capazes de visualizar o $\log$ de ações dos curadores, são responsáveis pelo cadastro de novos curadores, novas cidades e novas categorias na plataforma. Caso uma cidade ainda não esteja cadastrada, existe um formulário disponível na plataforma para que seja feita a solicitação de cadastro. Esse formulário é encaminhado para os administradores que, em até 48 horas, cadastram a cidade solicitada. Esse prazo consiste, majoritariamente, em procurar um curador para a cidade que está sendo solicitada. Por fim, os consumidores podem acessar a plataforma para procurar por algum produto ou serviço. São disponibilizados diversos filtros que podem ser combinados: filtro por cidades, por bairros e por categorias de produtos. Além disso, por meio de um plugin de integração com o Facebook, os consumidores podem deixar comentários sobre os produtos e/ou serviços, digitalizando a tradicional propaganda de boca a boca.

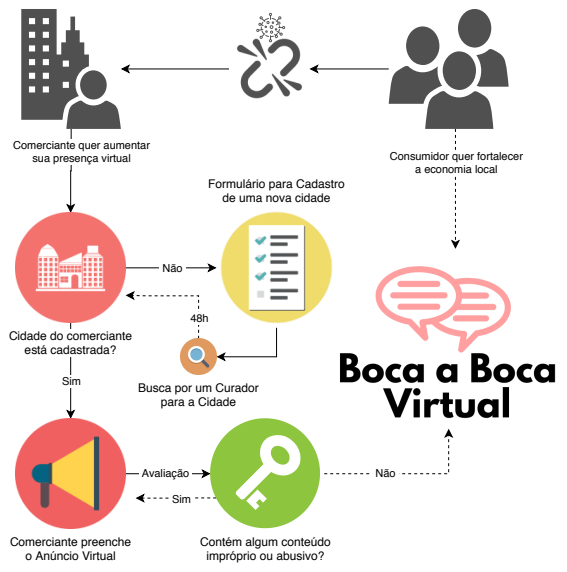

Figura 2: Fluxograma do Boca a Boca Virtual

\subsection{Funcionalidades Gerais}

A plataforma é composta por três ações principais: cadastrar uma cidade, um curador ou empreendimentos. Para se realizar a solicitação de cadastro de uma cidade, existe um formulário no qual devem ser preenchidas as informações: nome, e-mail do solicitante e nome da cidade que se deseja cadastrar. O solicitante ainda pode deixar alguma mensagem provendo informações extras que julgar relevantes. Esse processo de criação tem um prazo máximo de 48 horas para ser concluído e, quando ocorre, uma notificação é enviada ao solicitante. Uma informação importante, que demonstra que existe a demanda, é que muitas das cidades cadastradas na plataforma foram solicitadas por consumidores interessados em terem seus empreendimentos locais disponíveis na plataforma.

Conforme mencionado anteriormente, para que uma cidade possa receber cadastro de empreendimentos, a mesma precisa ter associado um curador. Normalmente, o convite para ser curador é feito ao usuário que fez o pedido de cadastro da cidade. Na indisponibilidade do mesmo, hoje contamos com colaboração dos alunos do curso de Ciência da Computação da UFSJ. Muitos deles, hoje, têm dedicado de 20 minutos à uma hora na atividade de curadoria. $\mathrm{O}$ cadastro do curador é feito diretamente pelo administrador da plataforma. Atualmente, estamos desenvolvendo um funcionalidade para que usuários possam solicitar atuar como curador.

Com a cidade e o curador definidos, um novo negócio pode ser cadastrado. Para isso, um formulário precisa ser preenchido e, no final deste, é possível visualizar uma prévia do anúncio no Boca a Boca Virtual, permitindo que informações sejam corrigidas, alteradas ou excluídas antes de se enviar para a análise. Na análise, a visualização prévia também fica habilitada para o curador da cidade, que pode verificar se imagens que estão sendo cadastradas na plataforma, bem como o conteúdo informativo da página, violam algumas das normas para anúncios na plataforma. Apesar deste processo manual de verificação por parte dos curadores, conseguimos ter um rápido retorno sobre a aprovação, ou rejeição, do anúncio de um comerciante. Em caso de rejeição, um e-mail é enviado para o endereço informado no cadastro do anúncio, explicando os motivos que justificaram sua rejeição.

\subsection{Funcionalidades do Administrador}

Como já comentado, o administrador é o responsável pelo cadastro de cidades, curadores, categorias e a visualização dos logs de ação na plataforma. Começando pelo cadastro de cidades e categorias, eles são feitos pelos administradores pois são dados extremamente sensíveis a erros de escrita. Não é à toa que existe um formulário solicitando o cadastro de cidade, pois somente cidades já cadastradas - e que estão escritas da maneira correta e associadas ao estado correto - podem ser preenchidas no formulário de cadastro do negócio. Além do mais, cidades cadastradas na plataforma precisam de uma imagem que a definam, pois elas servirão como capa para a página de listagem dos negócios de uma cidade.

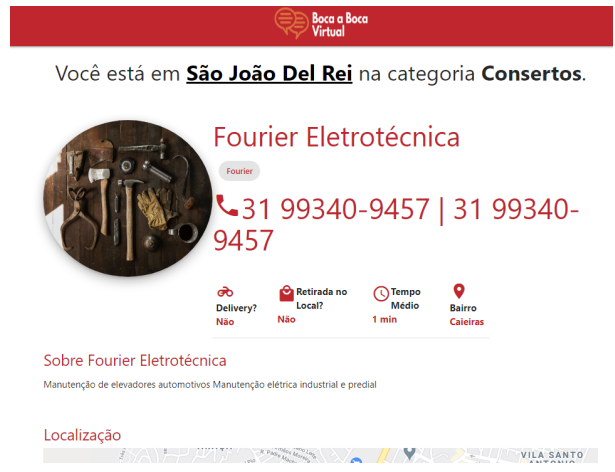

Figura 3: Anúncio com Logo Padrão

Categorias também seguem a mesma linha das cidades, um novo negócio só pode ser incluído em uma das categorias pré-definidas, pois além de estarem escritas da maneira correta, elas servem para definir logos padrões para negócios que não possuem esse tipo de imagem. Por exemplo, um técnico de informática recém-formado, que não possui uma logo que descreva seu negócio, pode se incluir na categoria de Informática e não salvar nenhuma imagem para essa logo. Nesse caso, seu anúncio vai conter, como logo, imagens padrão para a categoria Informática, tornando este anúncio mais intuitivo e chamativo, como mostra a Figura 3. Assim, visando não somente garantir a escrita correta de categorias, mas também incluir imagens padrão para logos, a categoria também é de responsabilidade do administrador. Novas categorias podem ser solicitadas 
via e-mail, sendo cadastrada caso haja uma demanda mínima de negócios que se enquadrem nessa nova categoria. Caso um negócio não tenha sua categoria disponível, ele é incluído, por padrão, na categoria 'Outros'.

Os curadores também são cadastrados pelos administradores e precisam ter familiaridade com as operações básicas do banco de dados, uma breve disponibilidade de horário e serem confiáveis para verificar possíveis conteúdos inapropriados nos anúncios que serão realizados. Todas as suas ações ficam armazenadas num $l o g$ de ações, disponível para o administrador, que, caso verifique alguma irregularidade, pode entrar em contato com o curador, desfazer alguma de suas ações ou desligá-lo da plataforma.

\subsection{Funcionalidades do Curador}

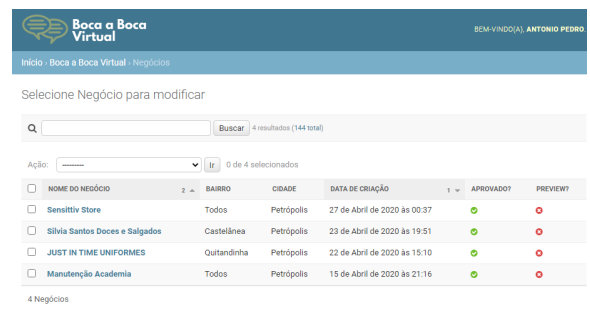

Figura 4: Sistema Interno para Curadores

Conforme mencionado, os curadores são os responsáveis pela validação das informações fornecidas pelos empreendedores e/ou autônomos. Para isso, os curadores fazem uso da visualização prévia de um anúncio para verificarem se o anúncio contém alguma imagem inapropriada ou textos ofensivos na descrição do produto, ou serviço. Não havendo nenhum desses problemas, o anúncio é aceito e cadastrado na plataforma, ficando disponível imediatamente para os usuários. Caso tenham alguma irregularidade, os curadores notificam pelo e-mail informado no cadastro do negócio, as irregularidades do anúncio, estando disponíveis para eventuais dúvidas. Ademais, eles também são responsáveis por alterar eventuais informações contidas nos anúncios, devendo estas novas informações serem notificadas pelo comerciante ao curador da cidade que o anúncio foi publicado, via e-mail. No seu acesso interno da plataforma, cada curador tem a sua disposição uma lista de negócios já aprovados e que não foram avaliados ainda, como mostra a Figura 4.

\subsection{Funcionalidades do Empreendedor}

Se os administradores e curadores são o "como funciona" do Boca a Boca Virtual, o empreendedor é o "por que fazer funcionar". Num cenário de danos incalculáveis para a economia local, pequenos comerciantes, prestadores de serviços autônomos e novos empreendedores não tinham onde divulgar seus trabalhos e produtos numa plataforma única e dedicada a isso. Apesar de existirem grupos em redes sociais voltados para isso, o empreendedor deve sempre "repostar" seu anúncio para que este sempre esteja no topo do feed. O Boca a Boca Virtual foi feito para unificar os produtos e serviços da economia local de cada cidade, permitindo que uma vez cadastrado, esteja sempre disponível e acessível para novos usuários, novos clientes. Para isso, ele deve preencher o formulário de cadastro disponível na página principal dessa plataforma para criar um anúncio virtual, preenchendo todas as informações necessárias, entre elas alguns dados pessoais para o controle interno da aplicação (como o e-mail, que é usado para os curadores entrarem em contato sobre uma eventual irregularidade em um anúncio, mas não é disponibilizado no anúncio). As Figuras 5a, 5b, 5c e 5d ilustram os passos que norteiam o cadastro do anúncio de um negócio na plataforma.

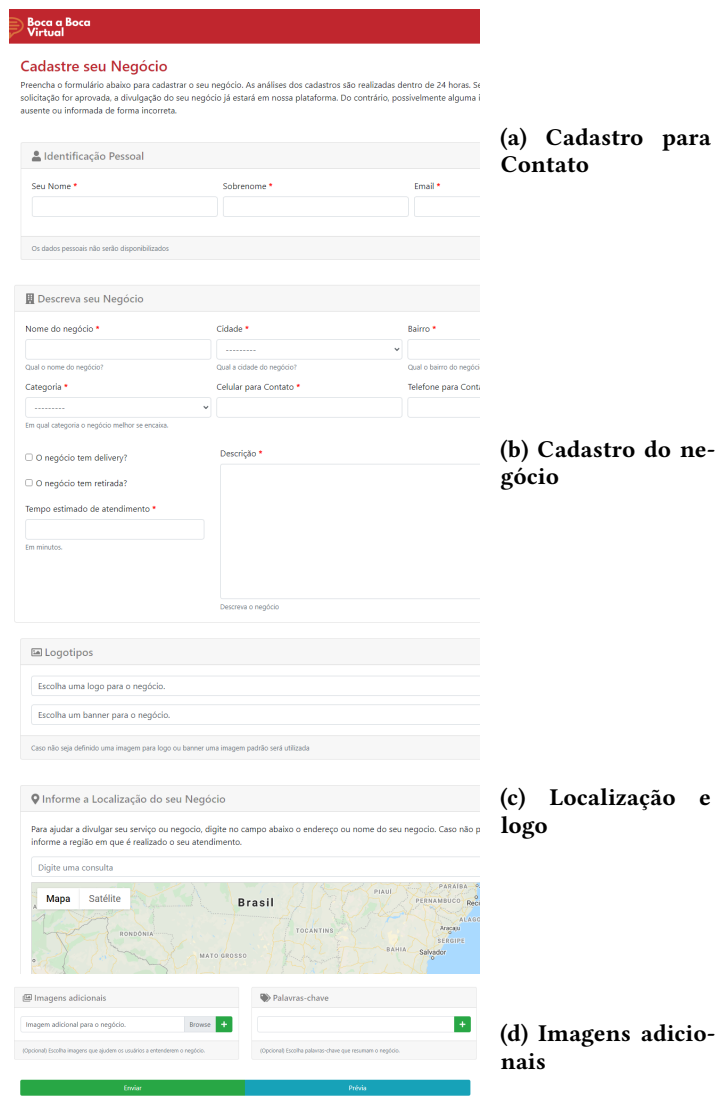

Figura 5: Formulário de Cadastro para Anúncios

Existem 6 tipos de dados no cadastro de um anúncio no Boca a Boca Virtual, são eles:

- Dados Pessoais: para controle interno da aplicação e que permitem um contato via e-mail entre curador e empreendedor.

- Descrição do Negócio: dados que descrevem o negócio de maneira geral e são obrigatórios, como Nome, Telefone para contato, se possui delivery entre outros.

- Logotipo: uma imagem que sumariza o negócio, isto é, uma logo (que fica visível na lista de estabelecimentos de uma cidade). Caso o logo não seja fornecido, serão utilizados imagens padrões da categoria que o anúncio está inserido.

- Imagens Adicionais: são imagens adicionais do serviço ou produto que está sendo oferecido, como imagens das marmitas que são vendidas.

- Palavras-chaves: palavras que resumem o negócio.

- Geolocalização: funcionalidade que permite que, para aqueles que possuem uma loja física, fiquem "marcados" no Google, o que aumenta sua visibilidade e presença digital, não somente no cenário atual, mas também no pós-pandemia.

\section{Resultados Alcançados}

Nossa plataforma foi lançada em abril de 2020 e hoje conta com 144 estabelecimentos cadastrados, de 38 cidades oriundas de cinco 
estados diferentes. Atualmente, esses estabelecimentos estão divididos em 13 categorias distintas: alimentação; consertos; farmácia; supermercado; automóveis; vestuário; educação; animais; beleza; turismo; saúde; informática e outros.

\begin{tabular}{lrrr} 
Cidade & População & Área $\left(\mathrm{km}^{2}\right)$ & Densidade $\left(\mathrm{hab} . / \mathrm{km}^{2}\right)$ \\
\hline São João Del Rei & 90497 & 1452.002 & 62.325672 \\
Entre Rios de Minas & 15380 & 456.796 & 33.669297 \\
Belo Horizonte & 2521564 & 331.354 & 7609.8795 \\
Resende Costa & 11540 & 618.312 & 18.663717
\end{tabular}

Tabela 1: Estimativas populacionais para os municípios

Primeiramente é importante caracterizar as cidades que a aplicação teve mais impacto (por número de estabelecimentos cadastrados). Na Figura 6 mostra que grande parte da aplicação teve impacto nas cidades de Minas Gerais. A maioria das cidades com mais cadastros possuem uma população pequena (Tabela 1), exceto Belo Horizonte, trazendo uma boa perspectiva sobre o público que foi impactado pela aplicação. Supomos que quanto maior a densidade demográfica da cidade mais interessante e impactante se torna nossa aplicação pela natureza interativa e social, se a cidade é muito densa populacionalmente então é mais apta a interações sociais.

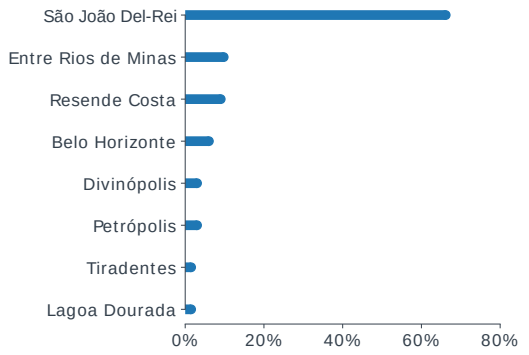

Figura 6: Estabelecimentos por Cidades (\% do Total)

Outro fato relevante a se destacar é que mais de $50 \%$ dos estabelecimentos cadastrados são relacionados a atividades essenciais (i.e. alimentação e saúde). Além disso, grande parte dos estabelecimentos apresentam um serviço de retirada ao invés de delivery pelo seu custo, o que se trata de uma característica que está bem mais associada à estabelecimentos de cidades do interior. Por outro lado, ainda existem estabelecimentos que consegue fazer uso de serviços de delivery (e.g., Uber Eats e ifood), mesmo com os custos associados, e os mesmos se concentram em Belo Horizonte e São João Del Rei.

\section{Conclusões}

Em constante contato com as secretarias municipais de várias das cidades cadastradas, em especial as cidades do interior de Minas Gerais, o retorno que temos recebido dessas autoridades é muito positivo, mencionando que a plataforma tem sido muito importante para os pequenos produtores. Algumas dessas cidades vêm fazendo campanhas publicitárias mencionando a importância do consumo de produtos locais. Essas campanhas, associadas ao Boca a Boca Virtual, vêm fortalecendo as economias locais. Um segundo aspecto importante a se mencionar é que a integração de nossa plataforma com o Google Maps tem possibilitado a indexação desses empreendimentos pela máquina de busca do Google, divulgando-os nacionalmente (muitos não possuíam referência na Web) e aumentando consideravelmente seus potenciais consumidores. Resende
Costa que, por exemplo, é localmente conhecida pelo artesanato têxtil, vem recebendo atenção e contatos de diversas cidades do Brasil.

Parte do sucesso da ferramente majoritariamente no interior de Minas Gerais está associado à divulgação que tivemos por parte da impressa regional, onde pudemos apresentar nossa plataforma em diversos meios de comunicação, com destaque para o jornal $\mathrm{O}$ Tempo (https://www.otempo.com.br/o-tempo-betim/federal-desao-joao-del-rei-cria-catalogo-online-de-pequenos-empreendim entos-1.2330929) e a Rede Minas (https://youtu.be/3AbvGhBOcV8). Acreditamos que, com uma divulgação mais ampla, poderemos ampliar o total de cidades e pequenos empreendedores atendidos.

\section{Acknowledgments}

Este trabalho teve a colaboração voluntária de alunos de Ciência da Computação da UFSJ, sejam como curadores, sejam como grandes divulgadores. Nossos agradecimentos a Ana Letícia, Ana Roberta, Bárbara Boechat, Bruce Williss, Gabriel Carneiro, Henique Jefferson, Igor Batista, Juliana Araújo, Lucas Rômulo, Luccas Guidio, Matheus Balbino, Rafael Paiva, Sidney Junior, Theo Valencio e Valney Faria.

\section{Referências}

[1] The Apache Software Foundation. 2020. The Apache HTTP Server Project. https: //www.apache.org/

[2] Django REST framework. 2020. Django REST framework. https://www.djangorest-framework.org

[3] Google. 2020. Angular One framework. Mobile \& desktop. https://angular.io/

[4] Google. 2020. Google Maps APIs de geolocalização. https://cloud.google.com/mapsplatform/

[5] The PostgreSQL Global Development Group. 2020. PostgreSQL The World's Most Advanced Open Source Relational Database. https://www.postgresql.org/

[6] Materialize. 2020. A modern responsive front-end framework based on Material Design. https://materializecss.com/

[7] Christian Prehofer and Ilias Gerostathopoulos. 2017. Chapter 3 - Modeling RESTful Web of Things Services: Concepts and Tools. In Managing the Web of Things, Quan Z. Sheng, Yongrui Qin, Lina Yao, and Boualem Benatallah (Eds.). Morgan Kaufmann, Boston, 73 - 104. https://doi.org/10.1016/B978-0-12-809764-9.00004-4

[8] SENTRY. 2020. SENTRY Application Monitoring Platform and Error Tracking Software. https://sentry.io/

[9] Inc Slack Technologies. 2020. slack Aqui o trabalho acontece. https://slack.com/

\section{Currículos}

Pablo Cecilio: Técnico em Eletrônica pelo COLTEC/UFMG (1996). Atualmente é aluno do curso de Ciência da Computação da UFSJ e vem realizando um trabalho de iniciação científica que versa sobre estratégias de modelagem de tópicos semanticamente enriquecidas. Lattes: http://lattes.cnpq.br/0639830593550189

Antonio Pedro: Técnico em Informática pelo SENAI Petrópolis (2016). Atualmente é aluno do curso de Ciência da Computação da UFSJ e vem realizando um trabalho de iniciação científica que versa sobre técnicas de redes complexas para análise de turismo em cidades. Lattes: http://lattes.cnpq.br/2385985653078595

Heitor Weneck: Técnico em Informática pelo CEFET-MG (2015). Atualmente é aluno do curso de Ciência da Computação da UFSJ e vem realizando um trabalho de iniciação científica que versa sobre estratégias de diversificação de recomendações de pontos de interesse. Lattes: http://lattes.cnpq.br/6543159151390118

Leonardo Rocha: Possui graduação (2003), mestrado (2005) e doutorado (2009) em Ciência da Computação pela UFMG e Pós-Doutorado na Ohio State University (2016). Atualmente é professor associado da UFSJ. Tem experiência na área de Ciência da Computação, com ênfase em planejamento de capacidade, mineração de dados, banco de dados e recuperação de informação. Lattes: http: //lattes.cnpq.br/8074447921818504 